\title{
We have the injury prevention exercise programme, but how well do youth follow it?
}

\author{
Nirmala K.P. Perera ${ }^{\mathrm{a}, \mathrm{b}, \mathrm{c}, \mathrm{d}}$, Martin Hägglund ${ }^{\mathrm{a}, \mathrm{b}, *}$ \\ a Division of Physiotherapy, Department of Medical and Health Sciences, Linköping University, Sweden \\ b Sport Without Injury ProgrammE (SWIPE), Linköping University, Sweden \\ c Centre for Sport, Exercise and Osteoarthritis Research Versus Arthritis, Nuffield Department of Orthopaedics, Rheumatology, and Musculoskeletal Sciences, \\ University of Oxford, Oxford, United Kingdom \\ d School of Allied Health, Human Services and Sport, Latrobe University, Melbourne, Victoria, Australia
}

\section{A R T I C L E I N F O}

\section{Article history:}

Received 24 May 2019

Received in revised form 5 November 2019

Accepted 13 November 2019

Available online 18 November 2019

\section{Keywords:}

Youth sports

Sports injuries

Neuromuscular training

Injury prevention exercise programme

Floorball

Knee control

\begin{abstract}
A B S T R A C T
Objectives: Describe the exercise fidelity and utilisation fidelity of the Knee Control injury prevention exercise programme (IPEP) in youth floorball alongside an intervention RCT.

Design: Observation study

Methods: 20 floorball team training groups (12 male, 8 female, age 12-17 years) from the intervention arm of an RCT were included. The Knee Control IPEP was implemented at the beginning of the season. A research team member attended a team training session twice in the season (first and second half of 26 week season) with a total 31 training sessions observed. An IPEP specific exercise fidelity checklist was used to assess how the programme was used.

Results: Of 535 individual Knee Control exercises observed (76\% of observations in males), $58 \%$ were performed correctly. Exercise fidelity was higher in females than in males ( $71 \% \mathrm{vs} 54 \%$, proportion difference $16 \%, 95 \%$ CI $7-25 \%, P=0.001$ ). The full Knee Control IPEP ( 7 exercises $x 3$ sets) was completed only during 4 of 31 (13\%) training sessions observed. The utilisation fidelity did not differ between sexes, and the mean number of completed exercises performed during the observations was 11 (SD 5).

Conclusions: The exercise fidelity to an IPEP in youth floorball players was low, with only three out of five exercises performed according to instructions. Furthermore, only half of the IPEP exercises were executed on average. To make IPEPs effective in youth floorball and other similar team-ball sports, more work is needed to understand the reasons for low exercise and utilisation fidelity.
\end{abstract}

(c) 2019 Sports Medicine Australia. Published by Elsevier Ltd. This is an open access article under the CC BY-NC-ND license (http://creativecommons.org/licenses/by-nc-nd/4.0/).

\section{Practical implications}

- Exercise and utilisation fidelity are important factors that contribute to the effectiveness of an injury prevention exercise programme (IPEP). The exercise fidelity was low, with only three out of five exercises performed according to instructions. Utilisation fidelity was also low, with only half of the IPEP exercises being executed on average. The preventive effect of potent IPEPs such as Knee Control could thus be hampered by low fidelity.

- Identifying reasons for low exercise and utilisation fidelity and exploring strategies to better support players and coaches may further improve the positive outcomes of the Knee Control IPEP and other similar programmes.

\footnotetext{
* Corresponding author.

E-mail address: martin.hagglund@liu.se (M. Hägglund).
}

- Over $90 \%$ of coaches believed that floorball injuries can be prevented, but only one in three coaches perceived their knowledge about injury prevention as good. One out of three coaches thought that regular use of an IPEP may actually increase injury risk suggesting this key stakeholder group have gaps in knowledge and believes relating to injury prevention and effects of IPEPs. As such current delivery strategies of IPEPs including Knee Control may be insufficient for translating new evidence to this group.

\section{Introduction}

Recent epidemiological data have demonstrated no reduction, or even increase, in knee injuries in collegiate athletes ${ }^{1}$ despite a large body of evidence supporting the efficacy of lower limb injury prevention programmes. ${ }^{2-4}$ Adherence to injury prevention exercise programmes (IPEP) in terms of performing the exercises as prescribed, with correct technique and with the prescribed volume is likely a key aspect to reduce injury risk. For instance, youth female 
soccer players who were highly adherent to IPEP exercises reported a higher (88\%) ACL injury reduction, while there was no difference in ACL injury rates between players with lowest adherence and those in the control group. ${ }^{5}$ Therefore, high exercise fidelity (i.e. performing exercises according to instructions) and utilisation fidelity (i.e. performing all exercises in an IPEP programme with the prescribed number of sets and repetitions) is a vital aspect of adherence and crucial to increase the effectiveness of an IPEP. ${ }^{6-8}$

Knee Control (Knäkontroll ${ }^{\circledR}$, SISU Idrottsböcker@, Sweden, 2005) is a Swedish IPEP developed for team sports (e.g. soccer, floorball, handball and basketball) and evaluated in a randomised controlled trial (RCT). ${ }^{3}$ The real-world impact of the Knee Control IPEP was evaluated using the Reach Effectiveness Adoption Implementation Maintenance (RE-AIM) framework ${ }^{9}$ in a questionnaire survey among youth soccer coaches. Three years after the Knee Control IPEP RCT, 91\% of youth soccer coaches (not previously included in the trial) in eight regional districts included in the study knew about the programme. Of these coaches, $74 \%$ had adopted the programme, and 35\% implemented it as prescribed. ${ }^{10}$ Hypothetically, the demonstrated effectiveness of the Knee Control IPEP could thus fall from a $64 \%$ reduction of ACL injuries in a controlled setting ${ }^{3}$ to a $12 \%$ reduction in the real-world context ${ }^{11}$ (i.e. $64 \%$ effectiveness in the RCT x $91 \%$ reach $\times 74 \%$ adoption x 35\% implementation, and $\mathrm{x} 82 \%$ maintenance). Consequently, with poor implementation, potent IPEPs that have high reach and adoption, fail to achieve optimal impact in the relevant sports setting. In a recent nation-wide follow-up of the effectiveness of the Knee Control IPEP in Swedish soccer, a $13 \%$ decrease of cruciate ligament injuries in females and $6 \%$ in males was seen 5 years after the nation-wide implementation of the Knee Control IPEP compared to 5 years preceding implementation. ${ }^{12}$ Such data give a strong impetus to understand determinants of exercise and utilisation fidelity to improve IPEPs in order to achieve large-scale and sustained impact beyond an RCT.

The exercise and utilisation fidelity of IPEPs is rarely evaluated alongside an RCT. Further, there is a lack of research into understanding implementation contexts and processes, and into intervention adaptation including barriers and facilitators to uptake and maintenance of IPEPs. ${ }^{13-15}$ For this reason, there has been growing interest in the evaluation of injury prevention interventions in sport settings. Barriers to the successful implementation of the Knee Control IPEP include low fidelity in terms of coaches modifying the programme to fit the needs of their team and players, sporadic use, or discontinued use. ${ }^{10}$ To test the generalisability of the Knee Control IPEP preventive efficacy in other team ball sports than soccer, a second cluster RCT was conducted in the 2017-18 season in youth floorball. A more in-depth evaluation of the implementation of the Knee Control IPEP in the floorball RCT could provide insight to inform evidence-based strategies to better target and support implementation. Therefore, we aim to describe exercise fidelity and utilisation fidelity of the Knee Control IPEP in youth floorball players alongside an intervention RCT.

\section{Methods}

The 15-min coach-led Knee Control IPEP contains six exercises that target core and lower limb strength, neuromuscular control, balance, jumping, and landing technique. To allow exercise progression and variation, each exercise has four different levels of difficulty and one corresponding partner exercise. Coaches were instructed to use the programme in their warm-up to all training sessions and matches during the 26 week season, starting at the easiest level and progressing as players' strength, balance, neuromuscular control and technique improve.

This observational study is part of the Sport Without Injury ProgrammE (SWIPE) floorball project, an RCT evaluating injury pre- vention efficacy of the Knee Control IPEP in youth floorball. Youth floorball teams that had not used the Knee Control IPEP or similar structured IPEP, in the year preceding the RCT, and trained at least twice weekly, were eligible for participation. It should be noted that despite this exclusion criteria, $42 \%$ of players $(56 \%$ females and 39\% males) had previous experience from using the Knee Control IPEP during the past year when they participated in other sports. ${ }^{16}$ The intervention group coaches plus $1-2$ players per team from clubs in two regions of Sweden were invited to a 45-60-minute seminar (implementation session) at the beginning of the floorball season (September 2017). During the implementation session, coaches received practical instructions about the correct execution of each of the six exercises (one legged knee squat, pelvic lift, two legged knee squat, the bench, the lunge and jump/landing technique) in the Knee Control IPEP. Exercises are performed in three sets with 8-15 repetitions per set (or 15-30s for the bench) (for more details about exercises in the Knee Control IPEP see Ref. ${ }^{3}$ ). During the implementation session, exercise progression and key performance techniques were demonstrated. Coaches were instructed to begin with the first exercise level (easiest), and when their players could perform the exercises correctly with good technique, they could progress to more difficult levels of the exercises. Also, the Knee Control IPEP was made available to coaches in video format, and written instructions with explanatory text and pictures were provided. After the initial implementation session, coaches were responsible for delivering the Knee Control IPEP to the players of their teams during the season.

Thirty-one teams (23 male and 8 female) with 301 players (194 male and 107 female) in 17 clubs participating at community level were included in the intervention arm of the RCT. ${ }^{16}$ These, in turn, formed 23 team training groups (some of the teams within the same club trained together), of which 20 team training groups (12 male, 8 female) were visited during this observation study. Three teams cancelled their training session when the fidelity observation was planned and owing to logistic reasons (e.g. travel) it was not possible to reschedule. Mean age of the players included in the intervention arm was 13.6 (SD 1.1) years (female 13.8 years, male 13.5 years). A member of the research group ( 1 physiotherapist, 2 physiotherapy students and 1 medical student) who were all familiar with the Knee Control IPEP attended one team training session in the first half (November to December 2017, 12 team visits) and one in the second half (February to March 2018, 19 team visits) of the floorball season. Observation visits were organised with the coach in advance and the interaction between the observer and the coaches and players was kept to a minimum during the visit. To reduce observer selection bias, the observer randomly selected players and allocated which Knee Control exercise to be assessed for their execution (exercise fidelity observation) before the training began. Therefore, players and coaches were unaware of which players and exercises were assessed. The observers assessed the exercises performed as correct or incorrect using a standardised Knee Control exercise fidelity checklist (Appendix A and criteria Appendix B), which was developed and tested for interrater reliability in youth soccer players (Kappa 0.800, substantial agreement). ${ }^{17}$ The observers watched a complete set of each exercise (between 8-15 repetitions) and the overall assessment was based on the performance of the full set. For example, an exercise observation was graded as correct if a player performed 10 out of 12 repetitions of an exercise with good technique. An exercise was considered as performed correctly if the observer scored 'correct' on all criteria for the exercise. Incorrect performance was indicated by recording of 'incorrect' for one or more criteria.

During the team training visit, the observer also collected information relating to the use of the Knee Control IPEP (utilisation fidelity observation), including information on when the exercises 
were performed (before, in the beginning, during, or after the training session), which exercises were performed, as well as the number of sets for each exercise and the overall number of exercises performed. Full utilisation fidelity was defined as the team performing all seven exercises (one legged knee squat counted as 2 exercises, 1 for each limb) of the Knee Control programme in 3 sets, thus giving a maximum of 21 exercise observations.

A baseline survey on demographic characteristics, injury risk perceptions, knowledge and attitudes towards injury prevention was distributed to all participating youth floorball team coaches before the start of the season in October 2017. A seven-point Likert scale was used for the question relating to injury risk perceptions. For the analysis responses of 1-3 were grouped as low risk, 4 was considered neutral and 5-7 were grouped as high risk. The same seven-point Likert scale and grouping strategy was used for questions relating to knowledge and attitudes towards injury prevention.

This study was approved by the Linköping Regional ethics committee (Project number Dnr 2017/294-31).

\section{Statistical analysis}

All statistical analyses were performed using SPSS ${ }^{\circledR} 25.0$ (IBM SPSS Statistics 2017). Descriptive statistics were used to describe exercise fidelity and utilisation fidelity. As the data were nonnormally distributed, a Mann-Whitney $U$ test was conducted to compare differences in Knee Control utilisation fidelity between sexes. A chi-square test was used to compare group proportions for categorical variables and proportion differences with $95 \%$ confidence intervals $(\mathrm{CI})$ were calculated. $P \leq 0.05$ was considered statistically significant.

\section{Results}

We performed 535 individual Knee Control exercise observations, 409 in male and 126 in female players. Of all exercises observed, 58\% (311/535) were performed correctly. Exercise fidelity was higher in female than male players (71\%, 89/126 observations vs $54 \%, 222 / 409$ observations, proportion difference $16 \%$, $95 \%$ CI 7-25\%, $P=0.001$ ). Among the individual exercises, fidelity was highest for lunges (71\%) and pelvic lifts (69\%), and lowest for one legged knee squat on the left leg (46\%) (Table 1). There was no difference in exercise fidelity during the first (57\%, 124/217 observations) and second $(59 \%, 187 / 318$ observations) half of the season, proportion difference $2 \%, 95 \% \mathrm{CI}-7-10 \%$, $(P=0.702)$. First-level exercises (Level A) were mostly performed during both seasonal observations. However, for the pelvic lift and the bench, the level of difficulty increased to Level $B$ and $C$ in the second half of the season (Table 2). Males performed more exercises with a higher level of difficulty ( $n=247,93$ and 59 for levels A, B and C/D, respectively) compared to females $(\mathrm{n}=88,26$, and $7, P=0.021)$.

In terms of the utilisation fidelity, full completion of the Knee Control IPEP ( 7 exercises $x 3$ sets) was performed in only four sessions ( 3 male and 1 female teams) out of the 31 team training session observations. The mean number of completed exercises performed was 11 (SD 5), and the utilisation fidelity did not differ between sexes. The number of sets executed for each single exercise is reported in Fig. 1. Most teams performed the IPEP at the beginning of the training $(55 \%, 17 / 31)$ or before the training $(42 \%$, $13 / 31$ ) and only one team performed the IPEP after the training session. The Knee Control exercises were mainly performed in the sports hall on a rubber or parquet floor $(87 \%, n=27)$ or in nearby facilities, e.g. hallway or outdoors $(13 \%, n=4)$.

Of the 39 coaches included in this study, $13 \%(n=5)$ were female. Mean age was 46 (SD 5) years (male 47 (SD 7) and female 42 (SD 1) years). Sixty-nine percent of coaches $(n=27)$ had basic and higher coach education, $23 \%(n=9)$ had basic coach education only, and three coaches had no coach education. On average coaches had 7 (SD 4) years (male 7 (SD 3) and female 11 (SD 8) years) experience coaching floorball teams. When the coaches were asked about their perception of risk of injury in floorball, $42 \%(n=16)$ perceived the risk as being low, $21 \%(n=8)$ were neutral and $37 \%(n=14)$ perceived the risk as high. The majority $(92 \%, n=36)$ thought injuries are preventable, whilst $33 \%(n=13)$ thought their knowledge about injury prevention was good, 33\% were neutral, and 33\% perceived their knowledge as poor. Similarly, 33\% believed that regular use of an IPEP could decrease injury risk, 33\% perceived no effect on injury risk, and 33\% believed the injury risk may increase.

\section{Discussion}

The principle findings of the study were that both utilisation fidelity and exercise fidelity of the Knee Control IPEP was low in this cohort of youth floorball players. Only half of the expected number of exercises were executed in the observed training sessions, and only three out of five exercises were performed correctly according to instructions. In other youth team ball sports, a similar trend was observed with only $9 \%$ of coaches performing the IPEP exactly as prescribed. ${ }^{18}$ Exercise fidelity in our study was lower than that reported for the FootyFirst IPEP in Australian football players (69\%), ${ }^{6}$ although that study was not in youth athletes, but higher than that reported from youth soccer players performing the Knee Control IPEP (48\%). ${ }^{17}$ Over the past two decades, sports medicine research has developed effective interventions for injury prevention in athletes. The demonstrated effectiveness of IPEPs might not fully translate into lasting real-world effects, ${ }^{11}$ which provides a strong impetus to understand the determinants of exercise and utilisation fidelity to achieve large-scale and sustained impact beyond an RCT. However, it was beyond the scope of this study to investigate the relationship between exercise fidelity, actual dosage (utilisation fidelity) and injury outcomes.

Coaches and athletes are key part of any IPEP adherence. ${ }^{15}$ One of the challenges encountered in a previous RCT of the Knee Control IPEP in female adolescent soccer was that team and player adherence deteriorated over the season..$^{5}$ Low adherence is just one of the major barriers evidence-based IPEPs face when translating from an RCT in a controlled environment to broad-scale reproduction in the real world under less controlled conditions. ${ }^{19}$ The effectiveness of an IPEP depends on several factors, including both exercise and utilisation fidelity. Low fidelity, therefore, could hamper the preventive effects of potent IPEPs such as Knee Control. To truly make preventive interventions in youth sports effective, we need to ensure that the intervention is well-received and used as intended by players and coaches. Identifying reasons for low exercise and utilisation fidelity and exploring strategies to better support players and coaches may further improve the positive outcomes of the Knee Control IPEP.

Coaches were instructed to start with the Level A exercises (easiest) and then progress through the various exercise difficulty levels as the players develop better technique and neuromuscular control. However, most of the exercises observed at both the beginning and the end of the season were Level A and B. Coach self-efficacy (i.e. their knowledge and confidence in leading the exercises for their players) might be a possible explanation for the lack of exercise progression and low exercise fidelity observed in our study. Although over $90 \%$ of coaches believed that floorball injuries can be prevented, only one in three coaches thought their knowledge about injury prevention was good. In a previous Knee Control IPEP implementation study in youth soccer, some coaches expressed a need for more support and education as they felt uncertain about the execution of the exercises. ${ }^{20}$ For this rea- 
Table 1

Exercise fidelity for the observed Knee Control exercises.

\begin{tabular}{|c|c|c|c|c|}
\hline Knee Control exercise & Performance criteria for the exercise & $\begin{array}{l}\text { Total } \\
\text { Correct, n (\%) }\end{array}$ & $\begin{array}{l}\text { Males } \\
\text { Correct, n (\%) }\end{array}$ & $\begin{array}{l}\text { Females } \\
\text { Correct, n (\%) }\end{array}$ \\
\hline $\begin{array}{l}\text { 1A. One legged knee squat } \\
\text { (right) }\end{array}$ & $\begin{array}{l}\text { Fidelity of the whole exercise } \\
\text { Fidelity of each criterion } \\
\text { - Knee over foot alignment } \\
\text { - Trunk control } \\
\text { - Stable hip } \\
\text { - Whole foot contact with ground } \\
\text { - Foot pointing forward }\end{array}$ & $\begin{array}{l}51(63) \\
59(73) \\
62(77) \\
72(89) \\
73(90)\end{array}$ & $\begin{array}{l}37(61) \\
40(66) \\
43(71) \\
52(85) \\
53(87)\end{array}$ & $\begin{array}{l}14(70) \\
19(95) \\
19(95) \\
20(100) \\
20(100)\end{array}$ \\
\hline $\begin{array}{l}\text { 1B. One legged knee squat } \\
\text { (left) }\end{array}$ & $\begin{array}{l}\text { Fidelity of the whole exercise } \\
\text { Fidelity of each criterion } \\
\text { - Knee over foot alignment } \\
\text { - Trunk control } \\
\text { - Stable hip } \\
\text { - Whole foot contact with ground } \\
\text { - Foot pointing forward }\end{array}$ & $\begin{array}{l}37 / 80(46) \\
48(60) \\
50(62) \\
50(62) \\
69(86) \\
71(89)\end{array}$ & $\begin{array}{l}27 / 61(44) \\
35(57) \\
33(54) \\
33(54) \\
51(84) \\
53(87)\end{array}$ & $\begin{array}{l}10 / 19(53) \\
13(68) \\
17(90) \\
17(90) \\
18(95) \\
18(95)\end{array}$ \\
\hline 2. Pelvic lift & $\begin{array}{l}\text { Fidelity of the whole exercise } \\
\text { Fidelity of each criterion } \\
\text { - Trunk control } \\
\text { - Hip extension } \\
\text { - Stable knee/s }\end{array}$ & $\begin{array}{l}49 / 71(69) \\
59(83) \\
49(69) \\
66(93)\end{array}$ & $\begin{array}{l}34 / 52(65) \\
41(79) \\
34(65) \\
47(90)\end{array}$ & $\begin{array}{l}15 / 19(79) \\
18(95) \\
15(79) \\
19(100)\end{array}$ \\
\hline 3. Two legged knee squat & $\begin{array}{l}\text { Fidelity of the whole exercise } \\
\text { Fidelity of each criterion } \\
\text { - Knee over foot alignment } \\
\text { - Upright position trunk } \\
\text { - Knee flexion to } 90^{\circ} \\
\text { - Feet pointing forward } \\
\text { - Smooth return from flexion to extension }\end{array}$ & $\begin{array}{l}41 / 73(56) \\
52(71) \\
53(73) \\
50(69) \\
65(89) \\
66(90)\end{array}$ & $\begin{array}{l}32 / 59(54) \\
40(68) \\
39(66) \\
51(90) \\
51(86) \\
52(88)\end{array}$ & $\begin{array}{l}9 / 14(64) \\
12(86) \\
14(100) \\
18(95) \\
14(100) \\
14(100)\end{array}$ \\
\hline 4. The bench & $\begin{array}{l}\text { Fidelity of the whole exercise } \\
\text { Fidelity of each criterion } \\
\text { - Elbows beneath shoulders } \\
\text { - Upper body and trunk straight } \\
\text { - For side-bench: one elbow beneath shoulder }\end{array}$ & $\begin{array}{l}40 / 77(52) \\
59(77) \\
42(54) \\
1 / 1(100)\end{array}$ & $\begin{array}{l}28 / 60(47) \\
42(70) \\
30(50) \\
-\end{array}$ & $\begin{array}{l}12 / 17(71) \\
17(100) \\
12(71) \\
1 / 1(100)\end{array}$ \\
\hline 5. Lunges & $\begin{array}{l}\text { Fidelity of the whole exercise } \\
\text { Fidelity of each criterion } \\
\text { - Knee over foot alignment } \\
\text { - Trunk control } \\
\text { - Stable hip } \\
\text { - Forward knee flexed to } 90^{\circ} \\
\text { - Foot pointing forward }\end{array}$ & $\begin{array}{l}54 / 76(71) \\
60(79) \\
55(72) \\
59(78) \\
69(91) \\
69(91)\end{array}$ & $\begin{array}{l}36 / 57(63) \\
41(72) \\
37(65) \\
40(70) \\
51(90) \\
50(88)\end{array}$ & $\begin{array}{l}18 / 19(95) \\
19(100) \\
18(95) \\
19(100) \\
18(95) \\
19(100)\end{array}$ \\
\hline 6. Jump and landing & $\begin{array}{l}\text { Fidelity of the whole exercise } \\
\text { Fidelity of each criterion } \\
\text { - Knee over foot alignment } \\
\text { - Trunk control } \\
\text { - Knee control } \\
\text { - Controlled jump and landing } \\
\text { - Soft landing } \\
\text { - Foot pointing forward at landing }\end{array}$ & $\begin{array}{l}46 / 77(60) \\
55(71) \\
62(80) \\
61(79) \\
61(79) \\
59(77) \\
70(91)\end{array}$ & $\begin{array}{l}35 / 59(59) \\
43(73) \\
46(78) \\
43(73) \\
46(78) \\
44(75) \\
52(88)\end{array}$ & $\begin{array}{l}11 / 18(61) \\
12(67) \\
16(89) \\
18(100) \\
15(83) \\
15(83) \\
89(99)\end{array}$ \\
\hline
\end{tabular}

son, it might be beneficial to allocate further support to coaches on the field and provide opportunities to upskill throughout the season, so that coaches are confident in delivering the Knee Control IPEP or similar programmes. Since such additional resources and manpower might not be available at community level youth sports other means of providing this support through e.g. online platforms, mobile applications, or social media should be explored. One out of three coaches thought that regular use of an IPEP may actually increase injury risk suggesting this key stakeholder group have gaps in knowledge and believes relating to injury prevention and effects of IPEPs similar to their peers in youth soccer and basketball. ${ }^{14,18}$ As such current delivery strategies of IPEPs including Knee Control may be insufficient for translating new evidence to this group.

The exercise fidelity was higher in females than in males, which corroborate previous findings from youth soccer. ${ }^{17}$ Still this was surprising considering that adolescent girls typically display more neuromuscular control deficits during jump/landing and cutting tasks than boys. ${ }^{21,22}$ We speculate that a heightened awareness of the increased risk of severe injuries in female athletes, and the benefits of IPEPs in reducing injury risk, may have positively influenced coaches and players in female teams. The first Knee Control IPEP RCT was performed in adolescent females and found effective to prevent acute knee and ACL injuries. ${ }^{3}$ Since positive results of the RCT gained attention from media and sports federations in Sweden it is likely that the Knee Control IPEP is well received by female athletes and coaches and this could encourage them to use the IPEP with high fidelity. In contrast, the Knee Control utilisation fidelity was higher in male floorball teams in terms of the number of exercises performed and this also warrants further investigation.

The SWIPE prevention RCT included only youth floorball teams that had not used the Knee Control IPEP in the past year. ${ }^{16}$ Although those teams that used the Knee Control IPEP were excluded, female players who play other sports, such as soccer, might have used Knee Control in these sports to a higher extent and therefore already being familiar with the exercises. Baseline data from the current cohort (including the intervention and control groups) show that 
Table 2

Level of difficulty for the assessed Knee Control exercises.

\begin{tabular}{|c|c|c|c|c|c|}
\hline Knee Control exercise & Exercise level & 1st half of the season (n) & 2nd half of the season (n) & Males (n) & Females (n) \\
\hline \multirow{4}{*}{$\begin{array}{l}\text { 1A. One legged knee squat } \\
\text { (right) }(\mathrm{n}=81)\end{array}$} & A & 25 & 40 & 48 & 17 \\
\hline & B & 0 & 3 & 0 & 3 \\
\hline & $\mathrm{C}$ & 2 & 4 & 6 & 0 \\
\hline & $\mathrm{D}$ & 1 & 6 & 7 & 0 \\
\hline \multirow{4}{*}{$\begin{array}{l}\text { 1B. One legged knee squat } \\
\text { (left) }(n=80)\end{array}$} & A & 25 & 39 & 48 & 16 \\
\hline & $\mathrm{B}$ & 0 & 3 & 0 & 3 \\
\hline & $\mathrm{C}$ & 2 & 4 & 6 & 0 \\
\hline & $\mathrm{D}$ & 1 & 6 & 7 & 0 \\
\hline \multirow{3}{*}{ 2. Pelvic lift $(n=71)$} & A & 32 & 21 & 37 & 16 \\
\hline & C & 1 & 16 & 15 & 2 \\
\hline & Partner & 0 & 1 & 0 & 1 \\
\hline \multirow{3}{*}{$\begin{array}{l}\text { 3. Two legged knee squat } \\
(n=73)\end{array}$} & A & 21 & 21 & 29 & 13 \\
\hline & $\mathrm{B}$ & 10 & 20 & 30 & 0 \\
\hline & Partner & 0 & 1 & 0 & 1 \\
\hline \multirow{5}{*}{ 4. The bench $(n=77)$} & A & 8 & 0 & 3 & 5 \\
\hline & B & 21 & 42 & 53 & 10 \\
\hline & $\mathrm{C}$ & 0 & 4 & 3 & 1 \\
\hline & $\mathrm{D}$ & 1 & 0 & 1 & 0 \\
\hline & Partner & & 1 & 0 & 1 \\
\hline \multirow{4}{*}{ 5. Lunges $(n=76)$} & A & 27 & 30 & 41 & 16 \\
\hline & B & 0 & 7 & 6 & 1 \\
\hline & $\mathrm{D}$ & 3 & 2 & 3 & 2 \\
\hline & Partner & 1 & 6 & 7 & 0 \\
\hline \multirow{5}{*}{$\begin{array}{l}\text { 6. Jump and landing } \\
(\mathrm{n}=77)\end{array}$} & A & 25 & 21 & 41 & 5 \\
\hline & B & 3 & 11 & 4 & 10 \\
\hline & $\mathrm{C}$ & 6 & 8 & 12 & 2 \\
\hline & $\mathrm{D}$ & 2 & 0 & 2 & 0 \\
\hline & Partner & 0 & 1 & 0 & 1 \\
\hline
\end{tabular}

A easiest exercise level; D most difficult exercise level.
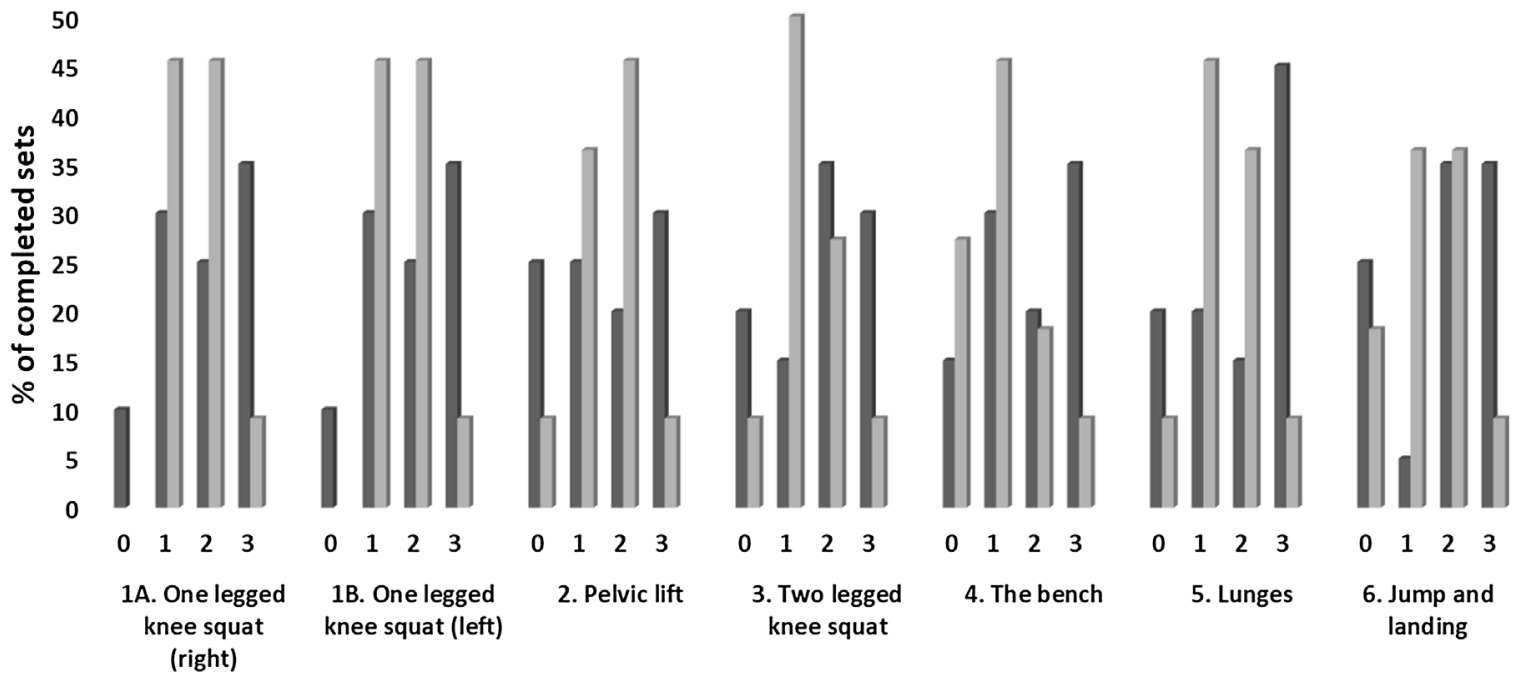

Knee Control exercise and set number

- Males Females

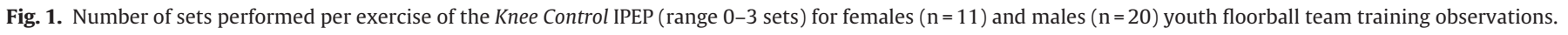

one in six female players and one in nine male players had regularly used the Knee Control IPEP when they participated in other sports during the past year. ${ }^{16}$ Exercise fidelity was, however, far from perfect among females, and as mentioned above utilisation fidelity was lower compared to male teams. Therefore, it is important to identify ways to support players and coaches to further improve exercise fidelity. Also, motivators and barriers for the Knee Control IPEP use might vary between sexes and should be considered in future studies.

One obvious limitation of an observational study like this is that the coaches and players were aware of the observers being present during the training session, thus introducing observer bias.
Consequently, coaches might lead the Knee Control IPEP more conscientiously than they usually would, or players might have executed the exercises to a higher standard knowing they were being observed. However, being observed could also have introduced more tension on coaches and/or players resulting in poorer programme and exercise execution due to, e.g. nervousness. To limit the observer impact the interaction with the team was kept to a minimum and the coaches and players were not aware which specific players and exercises were being assessed. Another limitation is that observation possibilities at times were less than optimal since observers kept 'out of the way' from the players to disturb them as little as possible. That is, observers might not have had 
the best view of a player to observe all the criteria for an exercise, for instance, the knee over foot alignment. Another important consideration is that we only observed teams/players at one or two training sessions (either once or twice in the season), and we do not know whether these observations are a true reflection of the actual utilisation and exercise fidelity throughout the rest of the season. Many teams have more than one coach, and since we did not record which coach delivered the Knee Control IPEP during the observation visit it was not possible to analyse the correlation between coach factors (age, sex, knowledge and experience of IPEPs) and intervention fidelity. Finally, it should be noted that four different observers collected the data. However, the Knee Control exercise fidelity checklist was previously evaluated with high inter-rater reliability in a similar cohort of youth athletes, ${ }^{17}$ and it should thus have minimal impact on the overall findings.

\section{Conclusion}

Our study provides insight into the evaluation of implementation outcomes of the Knee Control IPEP in youth floorball. The exercise fidelity was low, with only three out of five exercises performed according to instructions. Furthermore, utilisation fidelity was also low, with only half of the IPEP exercises being executed on average. To truly make IPEPs effective in youth floorball and other team-ball sports, future work is needed to understand the reasons for the low exercise and utilisation fidelity. Evidence-based strategies to better support players and coaches can ensure IPEPs are used as intended, thereby further improving the positive outcomes of such programmes.

\section{Financial support}

The Sport Without Injury ProgrammE is funded by the Swedish Research Council (2015-02414) and the Swedish Research Council for Sport Science (P2018-0167). Nirmala Kanthi Panagodage Perera was supported by Australia Awards-Endeavour Fellowship from the Department of Education and Training, Australia and Centre for Sport, Exercise and Osteoarthritis Research Versus Arthritis - Sports Grant (HFR02510).

\section{Contributorship}

Both authors contributed to all items in the ICMJE contributorship guidelines.

\section{Acknowledgements}

The authors acknowledge the participating players and coaches, Gustav Ljunggren RPT, MSc, Oskar Kjellander MS, Ida Elm RPT and Anton Svensson RPT for help with the data collection, and the Swedish Floorball Federation for administrative assistance. The Sport Without Injury ProgrammE is funded by the Swedish Research Council (2015-02414) and the Swedish Research Council for Sport Science (P2018-0167).

\section{Appendix A. Supplementary data}

Supplementary material related to this article can be found, in the online version, at doi:https://doi.org/10.1016/j.jsams.2019.11. 008.

\section{References}

1. Agel J, Rockwood T, Klossner D. Collegiate ACL injury rates across 15 sports: National Collegiate Athletic Association Injury Surveillance System data update (2004-2005 through 2012-2013). Clin J Sport Med 2016; 26(6):518-523.

2. Soligard T, Myklebust G, Steffen K et al. Comprehensive warm-up programme to prevent injuries in young female footballers: cluster randomised controlled trial. BMJ 2008; 337(a2469). http://dx.doi.org/10.1136/bmj.a2469.

3. Waldén M, Atroshi I, Magnusson H et al. Prevention of acute knee injuries in adolescent female football players: cluster randomised controlled trial. BMJ 2012; 344(e3042). http://dx.doi.org/10.1136/bmj.e3042.

4. Longo U, Loppini M, Berton A et al. The FIFA 11+ program is effective in preventing injuries in elite male basketball players: a cluster randomized controlled trial. Am J Sports Med 2012; 40(5):996-1005

5. Hägglund M, Atroshi I, Wagner P et al. Superior compliance with a neuromuscular training programme is associated with fewer ACL injuries and fewer acute knee injuries in female adolescent football players: secondary analysis of an RCT. Br J Sports Med 2013; 47(15):974-979.

6. Fortington L, Donaldson A, Lathlean T et al. When' just doing it' is not enough: assessing the fidelity of player performance of an injury prevention exercise program. J Sci Med Sport 2015; 18(3):272-277.

7. Leeuw M, Goossens M, de Vet $\mathrm{H}$ et al. The fidelity of treatment delivery can be assessed in treatment outcome studies: a successful illustration from behavioral medicine. J Clin Epidemiol 2009; 62(1):81-90.

8. Silvers-Granelli H, Bizzini M, Arundale A et al. Higher compliance to a neuromuscular injury prevention program improves overall injury rate in male football players. Knee Surg Sports Traumatol Arthrosc 2018; 26(7): 1975-1983.

9. Virginia Polytechnic Institute and State University. What is RE-AIM?, 2018. Available at: http://www.re-aim.org/about/what-is-re-aim/. Accessed 10 July 2018.

10. Lindblom $\mathrm{H}$, Waldén $\mathrm{M}$, Carlfjord $\mathrm{S}$ et al. Implementation of a neuromuscular training programme in female adolescent football: 3-year follow-up study after a randomised controlled trial. Br J Sports Med 2014; 48(19): $1425-1430$.

11. O’Brien J, Hägglund M, Bizzini M. Implementing injury prevention: the rocky road from RCT to real world injury reduction. Aspetar Sports Med J 2018:70-76.

12. Åman $\mathrm{M}$, Larsén $\mathrm{K}$, Forssblad $\mathrm{M}$ et al. A nationwide follow-up survey on the effectiveness of an implemented neuromuscular training program to reduce acute knee injuries in soccer players. Orth J Sports Med 2018; 6(12):2325967118813841.

13. O'Brien J, Finch C. The implementation of musculoskeletal injury-prevention exercise programmes in team ball sports: a systematic review employing the RE-AIM framework. Sports Med 2014; 44(9):1305-1318.

14. McKay C, Steffen K, Romiti M et al. The effect of coach and player injury knowledge, attitudes and beliefs on adherence to the FIFA 11+ programme in female youth soccer. Br J Sports Med 2014; 48(17):1281-1286.

15. Steffen K, Meeuwisse W, Romiti M et al. Evaluation of how different implementation strategies of an injury prevention programme (FIFA 11+) impact team adherence and injury risk in Canadian female youth football players: a cluster-randomised trial. Br J Sports Med 2013; 47(8):480-487.

16. Perera N, Åkerlund I, Hägglund M. Motivation for sports participation, injury prevention expectations, injury risk perceptions and health problems in youth floorball players. Knee Surg Sports Traumatol Arthrosc 2019; 27(11):3722-3732. http://dx.doi.org/10.1007/s00167-019-05501-7.

17. Ljunggren G, Perera N, Hägglund $M$. Inter-rater reliability in assessing exercise fidelity for the injury prevention exercise programme Knee Control in youth football players. Sports Med Open 2019; 5(1):35.

18. Norcross M, Johnson S, Bovbjerg V et al. Factors influencing high school coaches' adoption of injury prevention programs. J Sci Med Sport 2016; 19(4):299-304.

19. Owoeye O, McKay C, Verhagen E et al. Advancing adherence research in sport injury prevention. Br J Sports Med 2018; 52(17):1078-1079.

20. Lindblom $\mathrm{H}$, Carlfjord S, Hägglund $M$. Adoption and use of an injury prevention exercise program in female football: a qualitative study among coaches. Scand J Med Sci Sports 2017; 28(3):1295-1303.

21. Hewett T, Myer G, Ford K. Decrease in neuromuscular control about the knee with maturation in female athletes. J Bone Joint Surg Am 2004; 86(8): 1601-1608.

22. Landry S, McKean K, Hubley-Kozey C et al. Gender differences exist in neuromuscular control patterns during the pre-contact and early stance phase of an unanticipated side-cut and cross-cut maneuver in 15-18 years old adolescent soccer players. J Electromyogr Kinesiol 2009; 19(5): e370-e379. 